\title{
New Mathematical Modeling of Three-Level Supply Chain with Multiple Transportation Vehicles and Different Manufacturers
}

\author{
Amir Sadeghi * \\ PhD Student, Department of \\ Industrial Management, \\ College of Management and \\ Accounting, \\ South Tehran Branch, Islamic Azad \\ University, \\ Tehran, Iran
}

\author{
Amir Farmahini Farahani \\ PhD Student, Department of \\ Industrial Engineering, \\ South Tehran Branch, Islamic Azad \\ University, \\ Tehran, \\ Iran
}

\author{
Hossein Beiki \\ Faculty Member, Department of \\ Industrial Engineering, \\ Naragh Branch, Islamic Azad \\ University, \\ Naragh, \\ Iran
}

\begin{abstract}
Nowadays, no industry can move in global markets individually and independently of competitors because they are part of a supply chain and the success of each member of the chain influences the others. In this paper, the issue of three-level supply chain with several products, one manufacturer, one distributor, and several customers is reviewed. In the first part of the chain, one type of vehicle and in the second part of the chain, two types of vehicles are used. The proposed model of this paper is a mixed integer planning integrated model. The model is considered to minimize costs, including transportation, inventory, and shortage penalty cost. This paper is about the proposed approach for development of quantitative models in the field of three-level supply chain and theoretical research and presents a case study of sending produced rolls by Mobarakeh Steel Structure Company to "Sazeh Gostar Saipa (S.G.S)" and then to suppliers. The solution proposed in this paper is imperialist competitive algorithm which is solved in 20 different sizes, and the results in small size are compared with GAMS.
\end{abstract}

Keywords-Transportation; Mathematical Model; Logistic Costs; Imperialist Competitive Algorithm

\section{INTRODUCTION}

In a supply chain, transportation is an activity that influences all elements from the beginning of production until the delivery of products to customers; and in all activities, an efficient transportation significantly influences the reduction and augmentation of costs. Given the importance of a supply chain, this study attempts to propose a mathematical model for a three-level supply chain with the aim of minimizing chain costs so that products (rolls produced by Mobarakeh Steel Company) are transported from Mobarakeh Steel Company to Sazeh Gostar Saipa Company using one type of vehicle and then from Sazeh Gostar Saipa to suppliers using two vehicles. The proposed model for this research is a mixed zero and one planning integrated model. The outputs of the model include the number of rolls transported from manufacturer to Sazeh Gostar Company and then from Sazeh Gostar to each supplier, roll shortage for suppliers, inventory level of rolls in stock at the end of each period, and departure time of vehicles in the period. This model is solved in 20 different sizes. To solve the problem in small and large sizes, GAMS software and imperialist competitive algorithm are used, respectively; and imperialist competitive answers are found to be superior. Each problem has been implemented five times, and the best solution (least cost) is obtained and then the standard deviation has been examined five times.

The overall outline of this paper is as follows: initially a brief review of literature is provided, then the mathematical model is presented in Section 2, and after evaluation solutions in Section 3. Section 4 shows numerical examples and results, conclusion is presented in Section 5. Boumool and Vinod [1] conducted the first attempts on planning transportation and inventory. They proposed a theoretical model that could determine the number of orders and transportation options at the same time. The purpose of this model was to minimize the total cost of transportation, ordering, and inventory maintenance. The model considers a fixed cost to carry each item. Yukuyuma [2] has proposed an optimization integrated model with a possible demand in which inventory control and transportation are taken into consideration simultaneously. Products of a distribution center are transported to several customers. He has proposed a method to locate re-order point, determine the amount of re-order, and the number of transported products so that the total cost of the inventory and transportation will be minimized. Kim [3] has reviewed the schedule of sending in a system consisting of a central stock and $\mathrm{n}$ retailers. In the studied transportation system, only one type of product is taken into consideration. The purpose of this paper is to minimize the inventory cost of retailers so that they do not face any shortage.

Asgari and Aghdasi [4] have proposed an integrated mathematical model to plan inventory and transportation decisions. This multi-objective model describes minimizing maintenance costs and buyer orders, minimizing transportation cost of manufacturer, minimizing possibility of delay in the delivery of parts to achieve timely delivery and maximum utilization transportation fleet capacity. The model is intended for several products of chain; and if the demand for products is certain, several types of vehicles are also used to send products. 
Young and Beyung Park [5] have examined scheduling issue of vehicles taking the service and delivery time into account to minimize the total travel time and product delivery delay to retailers. This model is solved with hybrid genetic algorithm and its objective function is mixed integer programming. Karabook [6] examined the allocation of tasks to manufacturers with the aim of determining optimal production plan so that work completion time is minimal. Different manufacturers may need different time to process each job. To solve this problem, an adopted genetic algorithm, which is a new mechanism called gene mutation was applied.

Chue, Cheng, and Lin [7] have studied different ways to minimize work completion time on a two-level supply chain. They postulated that there are two manufacturers in parallel form on the first level and there is a factory on the second level. Things come in certain groups and researchers assumed that a fixed setup time is required for each group. Zegardi [8], considered the production and scheduling of transportation in a two-level supply chain in this study. Its objective function minimizes the total delay and total deviation from work load contributed to manufacturers from shares allocated to them. Its mathematical model is mixed integer programming. MSGA is applied to solve this problem and it is also compared with genetic algorithm and the results show the superiority of MSGA to GA. In this study, it is assumed that manufacturers are located in many geographical areas. Numerical examples of this study consist of 6 works, 3 manufacturers, and 2 vehicles.

David Naso's [9] paper is a combination of timely production and transportation, indicating that timely delivery to customers is one of the most important aspects of supply chain management. This article assumes that outsource is sometimes necessary for production. In this research, both earliness and delay are prohibited and genetic algorithm was used to solve it. It has a two-level supply chain, its objective function aims to minimize costs including outsource cost, waiting time punishment cost, and transportation cost. Zandiyeh et al., [10] hypothesized that an unlimited number of sources are available to deliver completed works without the need for a long time to move them. Thus, in this article, the production and scheduling of air transportation has been considered at the same time. The whole problem consists of two sub-problems which are air transportation and scheduling of a vehicle taken into consideration simultaneously. Objective function minimizes the entire chain costs and the time needed to do things such as earliness costs, departure delay costs, and move costs. Ghasemi et al, [11] designed a mathematical model for inventory management by programming with multiple objectives, developing an objective multi-function mathematical model is the certain finding of this study whose input is supplier annual demand, production capacity of manufacturer, type of piece packing, etc. and its output includes, production volumes (the amount of orders), the amount of storage required for each partner at central stocks, scheduling of sent batch from partners, etc. where reducing transport costs, optimizing the times of sending shipments from suppliers, and reducing the number of received shipments in the parent company is taken into consideration; and ultimately regarding statistical population of the study which is Saipa Automotive Group, developed mathematical model is tested and its output is compared with actual values of Saipa Company. Ann Zhou et $a l$, [12] stated that inventory, routing, and scheduling are three main factors for the operation of supply chain. They reviewed inventory integrated model, routing, and scheduling in a twolevel supply chain, VNS algorithm is used to solve NP problem of their study; then the results of this algorithm is compared with those of other algorithms and the superiority of this algorithm is approved. In this model, there is only one supplier and each route starts from one supplier and ends up to this very same supplier.

Vehicle capacity is already identified. Objective function of this paper aims to minimize inventory and transportation costs. Gorouprasad Pundur [13], in this article, scheduling of production and distribution in two-level supply chain including a number of manufacturers, one stock and customer is taken into consideration. Each manufacturer produces various products with fixed production rate; customer demand is constant for each product at all times; and exact and heuristic methods are applied and compared to solve the model. The aim of objective function is to reduce costs, including inventory cost, distribution costs, and set-up cost. The model is of mixed integer non-linear programming model type. Behatnagar, Mehta, and Theo [14] tried to balance decision problems of programming and short-term scheduling in supply chain using dual models. Two transporting methods are presented in this article one of which is maritime transportation with longer delivery time and less delivery cost, and another one is air transportation with more delivery cost, less delivery time, and more accurate prediction of demand. Decisions of programming determine the amount of order and inventory in maritime transportation, while decisions of scheduling concern scheduling and amount of air transportation. Numerical results of the study show that this model leads to sustainable cost recovery in a wide range of operations of both methods.

Alyamam and Dedin [15] modeled integrated supply chain as a network project, this model balances stationary and mobile inventory maintenance costs, operation cost in less time, transportation cost and delay penalty cost in the delivery of customer orders.

Hisham al-Din, Serker, and Aisam [16] investigated a twostep retrieved model to produce an inventory system with the possibility of damage in transportation. The aim of this model is to minimize related costs. It has a heuristic solution that deviates slightly from accurate methods. The results indicate that optimizing scheduling depends heavily on the relation between parameters of lost sales cost and timely sales cost.

Osman and Demireli [17] studied accumulated economic problems and delivery scheduling for multi-stage supply chain, and investigated maximum inventory strategy, and identifying throughput and time cycle for maximum inventory simultaneously so that all costs are minimized. These two methods are combined by non-linear models with a hybrid algorithm. Based on numerical results of the presented model, given algorithm has obtained an optimal solution for largescale problems in a short time, thereby reducing costs by $16.3 \%$.

In Kim et al, paper [18], two models are proposed to minimize total costs of transportation and inventory 
maintenance in a two-level supply chain in which dynamic demand and product transportation take place from a distribution center to customers by one type of vehicle. Transportation costs include fixed transportation cost and fixed handling costs of materials related to customer. Their proposed model is intended only for one type of product, but the necessity of expanding this model in following areas was realized due to the variety of products in reality:

- In proposed model, transportation cost consists of the times of transportation.

- In proposed model, distributer is evaluated as well as manufacturers and customers.

- Several products (rolls with different dimensions) are used instead of one type of product.

- To send products from manufacturer to distributor, one kind of vehicle is used; and to send products from distributor to customers, two types of vehicles are used.

In an article by Zegardy et al, [19] production and transportation scheduling have been studied. Several vehicles with different transportation capacity and speed are used. This article assumes that all suppliers are in one location. It is extended in following ways:

- One supplier is used instead of several suppliers.

- Instead of minimizing the time to do things, costs are minimized.

\section{MATHEMATICAL MODEL}

In this section, scheduling model of transportation and inventory is proposed to minimize total cost of transportation, inventory and shortage penalty. First, applied assumptions and symbols are expressed:

\section{A. Assumptions}

- In the first part of chain, one type of vehicle is used to move goods, and in the second part of chain two types of vehicles with recognized transportation capacity are used.

- This model is intended for a product with different dimensions.

- Shortage is allowed and is in the form of lost sales.

- At the beginning of scheduling, vehicles are available and rolls will be transported immediately.

- Unloading and storage time is clear for vehicle.

- Demands of a supplier are met in each travel.

- Demand rate of a supplier is supposed to be clear for the manufacturer.

- Transportation cost only includes the cost of the times of transportation and it is different for each manufacturer according to distance.

- A 20-ton truck trailer is the vehicle from Mobarakeh
Steel Company to Sazeh Gostar and a 20-ton or a 10ton truck trailer can be the vehicle from Sazeh Gostar to suppliers.

- Only one type of 20-ton truck trailer is used.

- Production programme has been almost constant for any desired periods (weekly, monthly, and quarterly) through leveling.

- Storage at supplier is impossible, and demand for period t cannot be sent during earlier periods.

- A vehicle can move one time in period t from factory to stock or from stock to supplier.

B. Indices

I. Sum of all products (rolls with different dimensions)

i. Product index

J. Set of all suppliers (customers)

j. supplier index $(\mathrm{j} \in \mathrm{J})$

$\mathrm{K}$. Set of all vehicles from manufacturer to stock

k. vehicle index

$K^{\prime}$. Set of all vehicles from stock to supplier

$k^{\prime}$.Vehicle index $\left(\mathrm{k}^{\prime} \in \mathrm{K}^{\prime}\right)$

T. Set of all periods

t. Period index $(t \in T)$

\section{Parameters}

$\mathrm{a}_{\mathrm{k}}=$ fixed transportation cost between manufacturer and stock by vehicle $\mathrm{k}$

$\mathrm{b}_{\mathrm{jk}}=$ fixed transportation cost between stock and supplier $\mathrm{j}$ by vehicle $\mathrm{k}^{\prime}$

$\mathrm{h}_{\mathrm{it}}=$ maintenance costs per unit of product (roll $\mathrm{i}$ ) by stock in period $t$

$r_{i}=$ shortage penalty per unit of product (Roll i) in stock

$\mathrm{D}_{\mathrm{k}}=$ capacity of vehicle $\mathrm{k}$ according to weight to travel from manufacturer to stock

$\mathrm{D}_{\mathrm{k}^{\prime}}^{\prime}=$ capacity of vehicle $\mathrm{k}^{\prime}$ according to weight to travel from stock to supplier

$\mathrm{g}=$ stock capacity

$\mathrm{w}_{\mathrm{i}}=$ weight of each packet of product $\mathrm{i}$

$\mathrm{d}_{\mathrm{ijt}}=$ product demand $\mathrm{I}$ for supplier $\mathrm{j}$ in period $\mathrm{t}$

$\mathrm{ct}_{\mathrm{k}}=$ travel time from manufacturer to stock by vehicle $\mathrm{k}$

$\mathrm{ct}_{\mathrm{k}^{\prime} \mathrm{j}}^{\prime}=$ travel time from stock to supplier $\mathrm{j}$ by vehicle $\mathrm{k}^{\prime}$

$\mathrm{st}_{\mathrm{t}}=$ beginning of period $\mathrm{t}$

Fin $_{\mathrm{t}}=$ end of period $\mathrm{t}$ 


\section{Variables}

$\mathrm{X}_{\mathrm{ikt}}=$ number of product (roll i) transported from manufacturer to stock by vehicle $\mathrm{k}$ in period $\mathrm{t}$

$\mathrm{Q}_{\mathrm{ijk} \mathrm{t}_{\mathrm{t}}}=$ number of product (roll $\mathrm{i}$ ) transported from stock to the supplier $\mathrm{j}$ by vehicle $\mathrm{k}^{\prime}$ in period $\mathrm{t}$

$\mathrm{S}_{\mathrm{ijt}}=$ number of product shortage (roll i) for a supplier $\mathrm{j}$ in period $\mathrm{t}$

$\mathrm{In}_{\mathrm{it}}=$ number of product inventory $\mathrm{i}$ in stock at the end of period $t$

$\mathrm{Z}_{\mathrm{kt}}=$ Is taken 1 if vehicle $\mathrm{K}$ is sent to stock in period $\mathrm{t}$, otherwise is taken zero.

$\mathrm{Z}_{\mathrm{jk}^{\prime} \mathrm{t}}^{\prime}=$ Is taken 1 if vehicle $\mathrm{k}^{\prime}$ works for supplier $\mathrm{j}$ in period $\mathrm{t}$, otherwise is taken zero.

$\mathrm{c}_{\mathrm{kt}}=$ departure time of vehicle $\mathrm{K}$ from manufacturer to stock in period $\mathrm{t}$

$\mathrm{c}_{\mathrm{jk}}^{\prime} \mathrm{t}=$ departure time of vehicle $\mathrm{k}^{\prime}$ from stock to supplier $\mathrm{j}$ in period $\mathrm{t}$

\section{E. Formulating the problem mathematically}

Now, according to mentioned assumptions, symbols, and variables, mathematical model of problem is as follows:

\section{$\operatorname{Min} \mathbf{Z}$}

$\sum_{\mathbf{t}} \sum_{\mathbf{k}} \mathbf{a}_{\mathbf{k}}\left(\mathbf{z}_{\mathbf{k t}}\right)+\sum_{\mathbf{t}} \sum_{\mathbf{j}} \sum_{\mathbf{k}^{\prime}} \mathbf{b}_{\mathbf{j k}}\left(\mathbf{z}_{\mathbf{j} \mathbf{k}^{\prime} \mathbf{t}}^{\prime}\right)+\sum_{\mathbf{t}} \sum_{\mathbf{i}} \mathbf{h}_{\mathbf{i t}}\left(\mathbf{I n}_{\mathbf{i t}}\right)+$ $\sum_{\mathrm{i}} \sum_{\mathrm{t}} \sum_{\mathrm{j}} \mathbf{r}_{\mathrm{i}} \mathbf{s}_{\mathrm{ijt}}$

The aim of proposed mathematical model is to minimize total costs of transporting products from manufacturer to stock and from stock to customers, cost of inventory maintenance at the end of each period, and cost of product shortage penalty.

The first and second parts of objective function show transportation cost which is the product of fixed transportation cost in a zero and one variable indicating whether or not the given vehicle is used in each period.

The third part of the objective function represents total costs of inventory maintenance of products available in stock in different periods; the final part also reflects shortage penalty of products facing shortage in different periods.

$$
\begin{aligned}
& \text { s.t. } \\
& \mathbf{z}_{\mathbf{k t}} \geq \frac{\sum_{\mathbf{i}} \mathbf{w}_{\mathbf{i}} \mathbf{x}_{\mathbf{i k t}}}{\mathbf{D}_{\mathbf{k}}}
\end{aligned}
$$

$\forall \mathbf{k}, \mathbf{t}$

(2)

Limitation (2) shows the number of vehicle $\mathrm{k}$ used in each period to transport products from Mobarakeh Steel to Sazeh Gostar stock; in addition, it shows the low limit of the capacity of each vehicle.

$\mathbf{z}_{\mathbf{j} \mathbf{k}^{\prime} \mathbf{t}}^{\prime} \geq \frac{\sum_{\mathbf{i}} \mathbf{w}_{\mathbf{i}} \mathbf{Q}_{\mathbf{i j k}} \mathbf{t}}{\mathbf{D}_{\mathbf{k}^{\prime}}^{\prime}}$

$\forall \mathbf{k}^{\prime}, \mathbf{t}, \mathbf{j}$

(3)

Limitation (3) indicates the number of vehicles $k^{\prime}$ used in each period to transport products from Sazeh Gostar stock to suppliers; in addition, it indicates the low limit of the capacity of each vehicle. $\sum_{\mathbf{k}} \mathbf{x}_{\mathrm{ikt}}+\mathbf{I n}_{\mathbf{i},(\mathbf{t}-\mathbf{1})}-\sum_{\mathbf{k}^{\prime}} \sum_{\mathbf{j}} \mathbf{Q}_{\mathbf{i j k} \mathbf{k}^{\prime} \mathbf{t}}=\mathbf{I n}_{\mathrm{i}, \mathbf{t}}$ $\forall \mathbf{t}, \mathbf{i}$

Limitation (4) represents stock inventory variable. Product inventory $\mathrm{i}$ in stock at the end of period equals the number of products sent to Sazeh Gostar stock in different periods by available vehicles, as well as product inventory $i$ at the end of previous period less the number of product which is sent to supplier by all available vehicles.

$\mathbf{d}_{\mathrm{ijt}}=\sum_{\mathbf{k}^{\prime}} \mathbf{Q}_{\mathrm{ijk} \mathbf{k}^{\prime} \mathrm{t}}+\mathbf{s}_{\mathrm{ijt}}$

$\forall \mathbf{i}, \mathbf{j}, \mathbf{t}$ (5)

Limitation (5) shows the demand of each supplier is met; the demand of each supplier in each period equals the number of products sent to each supplier in different periods by available vehicles, as well as shortage of that product for each supplier.

$\sum_{\mathrm{i}} \mathbf{W}_{\mathrm{i}} \mathbf{I n}_{\mathrm{it}} \leq \mathbf{g}$

$\forall \mathbf{t}$

(6)

Limitation (6) represents stock capacity limitation. The volume of products stored in stock shall not exceed the useful capacity of stock. Left side of limitation shows the product of volume of products and their amount of inventory and right side manifests stock capacity.

$\sum_{\mathrm{i}} \mathbf{x}_{\mathrm{ikt}} \leq \mathbf{M Z}_{\mathrm{kt}}$

$\forall \mathbf{k}, \mathbf{t}$

(7)

Limitation (7) shows the relationship between two variables xikt and zkt .

$\sum_{\mathbf{i}} \mathbf{Q}_{\mathbf{i j k} \mathbf{k}^{\prime}} \leq \mathbf{M Z}_{\mathbf{j k}^{\prime} \mathbf{t}}^{\prime}$

$\forall \mathbf{k}^{\prime}, \mathbf{t}, \mathbf{j}$

(8)

Limitation (8) shows the relationship between two variables $Q_{i j k^{\prime} t}$ and $Z_{j k^{\prime} t}^{\prime}$.

$\mathrm{c}_{\mathrm{kt}} \geq \mathrm{c}_{\mathrm{k}, \mathrm{t}-1}+2 \mathrm{ct}_{\mathrm{k}}+\mathrm{T}+\mathbf{5}-\mathbf{m}\left(\mathbf{1}-\mathrm{z}_{\mathrm{k}, \mathrm{t}-1}\right)$

$\forall \mathbf{k}, \mathbf{t}>1$

Limitation (9) represents departure time of vehicle $\mathrm{k}$ to stock. This limitation shows that departure time of vehicle $\mathrm{k}$ to stock in each period is equal to departure time of each vehicle in previous period, as well as the sweep time of vehicle plus the time it takes to unload the vehicle in stock as well as rest periods for drivers.

$\mathbf{c}_{\mathbf{j k}^{\prime} \mathbf{t}}^{\prime} \geq \mathbf{c}_{\mathbf{j k} \mathbf{k}^{\prime}(\mathbf{t}-1)}^{\prime}+2 \mathbf{c t}_{\mathbf{j k}^{\prime}}^{\prime}+\mathbf{T}^{\prime}+5-\mathbf{m}\left(1-\mathbf{Z}_{\mathbf{j k} \mathbf{k}^{\prime}(\mathrm{t}-1)}^{\prime}\right)$

$\forall \mathbf{j}, \mathbf{k}^{\prime}, \mathbf{t}>1$

Limitation (10) represents departure time of vehicle $\mathrm{k}^{\prime}$ to suppliers. This limitation shows that departure time of each vehicle to stock in each period is equal to departure time of each vehicle in previous period, as well as the sweep time of vehicle plus the time it takes to unload the vehicle in stock as well as rest periods for drivers.

$\mathbf{s t}_{\mathrm{t}} \mathrm{z}_{\mathrm{kt}} \leq \mathrm{c}_{\mathrm{kt}} \leq \operatorname{Fin}_{\mathrm{t}} \mathrm{z}_{\mathrm{kt}}$

$\forall \mathbf{k}, \mathbf{t}$

(11)

$\mathbf{s t}_{\mathrm{t}} \mathbf{z}_{\mathbf{j k}^{\prime} \mathbf{t}}^{\prime} \leq \mathbf{c}_{\mathbf{j k}^{\prime} \mathbf{t}}^{\prime} \leq \mathrm{Fin}_{\mathrm{t}} \mathbf{z}_{\mathbf{j k}^{\prime} \mathbf{t}}^{\prime}$

$\forall j, k^{\prime}, t$ (12)

Limitations (11) and (12) show that departure time of each vehicle to the destination in the period must be between the beginning and the end of the period. 
$\sum_{\mathbf{j}} \mathbf{Z}_{\mathbf{j k}^{\prime} \mathbf{t}}^{\prime} \leq \mathbf{1}$

$\forall \mathbf{t}, \mathbf{k}^{\prime}$ (13)

Limitation (13) indicates that each vehicle is sent to one customer and the demand of one supplier can be met in each travel.

$\mathbf{c}_{\mathrm{kt}}, \mathbf{c}_{\mathrm{jk} \mathbf{t}}^{\prime} \geq \mathbf{0}$

(14)

$x_{i k t}, Q_{i j k}{ }^{\prime}, I_{i t}, S_{i j t}=$ Integer

(15)

$\mathbf{Z}_{\mathbf{k t}}, \mathbf{z}_{\mathbf{j} \mathbf{k}^{\prime} \mathbf{t}}^{\prime} \in(\mathbf{0}, \mathbf{1})$

(16)

Equation (14) indicates that departure time variables of vehicle from manufacturer to stock and departure time of vehicle from stock to suppliers are positive temporarily. Equation (15) also shows that variables of the number of products transported from manufacturer to stock and the number of transported products from stock to suppliers as well as the number of product shortage and inventory level are all integer variables. And relation (16) also indicates that the variable of use or non-use of any vehicle in each period is as zero and one.

\section{SOLUTION}

Like other evolutionary algorithms, this algorithm begins with some random initial population, and each of them is called a country. Some of the best elements of population (equivalent elite in GA) elected as imperialist. The remaining population is considered the colony. Depending on their power, imperialists attract the colonies with a special process. Total power of the empire depends on both forming parts that are imperialist country (the core) and its colonies. Mathematically, this dependency is modeled by defining imperial power as total power of imperialist country, plus a percentage of the average of its colonial power. Once early empires are formed, imperial competition will start among them. Each empire that fails to compete in colonial competition and increase its power (or at least fails to prevent its influence reduction) will be removed from colonial competition. Thus, the survival of an empire depends on its ability to attract and dominate the colonies of rival empires. As a result, during imperialist competitions, the power of larger empires gradually increases, and weaker empires will be removed. Empires are forced to develop their colonies to increase their own power. Over time, the colonies will approach empires in power and you see some kind of a convergence of power. At the final stage of imperialist competition, there is only one united empire in the world with the colonies whose position is very close to the imperialist country.

\section{A. Proposed pseudo-code Agorithm}

1) Select some random points on the function and form up early empires.

2) Move the colonies to the imperialist countries (matching policies)

3) If there is a colony of an empire whose cost is less than the imperialist country, change the colonial and imperialist position.
4) Count total cost of an empire (regarding the imperialists and their colonies costs).

5) Select a colony from the weakest empire and give it to the empire who most likely dominates it.

6) Remove weak empires.

7) If only one empire remains, stop and go back to 2 .

\section{B. Parameter adjustment}

As can be seen, the performance of an algorithm depends heavily on the intensity of its parameters. In this study, response surface methodology (RSM) is used to set parameters. Different levels of parameters can be coded as follows:

$$
X_{i}=\frac{r_{i}-\left(\frac{h+l}{2}\right)}{\left(\frac{h-l}{2}\right)}
$$

Where $h$ and 1 denote upper and lower surfaces of parameters, respectively; and $X_{i}$ and $r_{i}$ denote coded and actual values of parameters, respectively. At this point, the algorithm will be administered for different combinations of parameters and their different levels. Another input of RSM methodology is an index that can compare the algorithm for different combinations of parameters. In this study, the same value of objective function is used as a response. Adjusted values of parameters are shown in Table 1.

TABLE I. ADJUSTED PARAMETERS IN THE PROPOSED ALGORITHM

\begin{tabular}{|c|c|c|}
\hline Factors & $\begin{array}{l}\text { Optimal } \\
\text { coded value }\end{array}$ & $\begin{array}{l}\text { Optimal } \\
\text { real value }\end{array}$ \\
\hline n-Pop & 0.85 & 193 \\
\hline$N$-imp & -0.2 & 5 \\
\hline$P_{A}$ & 0.18 & 0.54 \\
\hline$P_{R}$ & -0.8 & 0.12 \\
\hline$E$ & 0.9 & 0.195 \\
\hline$B$ & -0.2 & 1.8 \\
\hline
\end{tabular}

\section{Numerical example}

To test the algorithm, 20 example problems are produced by Sazeh Gostar Company regarding given numerical range. The data are explained in Table 2.

\section{Solving the model}

GAMS 22.1 software is used to code and solve the model, computer specifications are $2.2 \mathrm{GHZ}$, RAM 4, which have been reported in Table 3. The first column of the table indicates the number of problems which are 20 . The second column shows the number of suppliers that is considered from 10 to 100 . The third column indicates the number of products which is considered from 5 up to 70 .

The fourth column shows obtained objective function values using GAMS software. Only 5 first samples had feasible answers, and for larger-scale problems, the imperialist competitive algorithm is used. Each of these samples was performed on a total of 5 times with the fifth column represents the best answer which had the least cost. The sixth column shows the standard deviation of 5 times of administration of each problem. The seventh column manifests computational problem solving time. The last column shows GAP which has been increased to 1.1 . 
TABLE II. PROBLEM DATA

\begin{tabular}{|l|l|l|}
\hline $\begin{array}{l}\text { Number of } \\
\text { products }\end{array}$ & $\begin{array}{l}\text { Number of } \\
\text { customers }\end{array}$ & Sample issue \\
\hline 1 & 10 & 5 \\
\hline 2 & 10 & 10 \\
\hline 3 & 10 & 20 \\
\hline 4 & 20 & 10 \\
\hline 5 & 20 & 20 \\
\hline 6 & 20 & 25 \\
\hline 7 & 30 & 10 \\
\hline 8 & 30 & 20 \\
\hline 9 & 30 & 25 \\
\hline 10 & 40 & 20 \\
\hline 11 & 40 & 25 \\
\hline 12 & 40 & 30 \\
\hline 13 & 70 & 30 \\
\hline 14 & 70 & 35 \\
\hline 15 & 70 & 40 \\
\hline 16 & 100 & 30 \\
\hline 17 & 100 & 40 \\
\hline 18 & 100 & 50 \\
\hline 19 & 100 & 60 \\
\hline 20 & 100 & 70 \\
\hline
\end{tabular}

TABLE III. RESULTS OF THE MODEL

\begin{tabular}{|c|c|c|c|c|c|c|c|}
\hline \multirow{2}{*}{$\begin{array}{c}\text { Pro. } \\
\text { No. }\end{array}$} & \multirow{2}{*}{$\begin{array}{r}\text { Sup. } \\
\text { No }\end{array}$} & \multirow{2}{*}{$\begin{array}{l}\text { Sam. } \\
\text { issue }\end{array}$} & \multirow{2}{*}{$\begin{array}{l}\text { OFV of } \\
\text { GAMS }\end{array}$} & \multicolumn{2}{|c|}{ OFV of ICA } & \multirow{2}{*}{$\begin{array}{c}\text { Cpu } \\
\text { Time } \\
\text { (sec) }\end{array}$} & \multirow[b]{2}{*}{ Gap } \\
\hline & & & & Mean & Std & & \\
\hline 1 & 10 & 5 & 3693276 & 3693276 & 50 & 15 & 0 \\
\hline 2 & 10 & 10 & 8792932 & 8836897 & 63 & 25 & 0.5 \\
\hline 3 & 10 & 20 & 95951810 & 96815376 & 98 & 35 & 0.9 \\
\hline 4 & 20 & 10 & 138442170 & 140241918 & 79 & 49 & 1.3 \\
\hline 5 & 20 & 20 & 1544783680 & 1561776300 & 101 & 78 & 1.1 \\
\hline 6 & 20 & 25 & - & 3901481030 & 97 & 90 & - \\
\hline 7 & 30 & 10 & - & 10721125650 & 110 & 110 & - \\
\hline 8 & 30 & 20 & - & 18455602650 & 124 & 132 & - \\
\hline 9 & 30 & 25 & - & 54754476050 & 132 & 156 & - \\
\hline 10 & 40 & 20 & - & 166157490090 & 109 & 230 & - \\
\hline 11 & 40 & 25 & - & 321982554408 & 107 & 276 & - \\
\hline 12 & 40 & 30 & - & 643457896800 & 147 & 290 & - \\
\hline 13 & 70 & 30 & - & $7.6 \times 10^{15}$ & 152 & 331 & - \\
\hline 14 & 70 & 35 & - & $8.2 \times 10^{18}$ & 132 & 359 & - \\
\hline 15 & 70 & 40 & - & $5.3 \times 10^{22}$ & 126 & 380 & - \\
\hline 16 & 100 & 30 & - & $4.9 \times 10^{25}$ & 128 & 690 & - \\
\hline 17 & 100 & 40 & - & $3.3 \times 10^{27}$ & 113 & 701 & - \\
\hline 18 & 100 & 50 & - & $2.8 \times 10^{30}$ & 143 & 725 & - \\
\hline 19 & 100 & 60 & - & $7.4 \times 10^{35}$ & 179 & 758 & - \\
\hline 20 & 100 & 70 & - & $6.9 \times 10^{41}$ & 168 & 790 & \\
\hline
\end{tabular}

\section{E. Graphs}

Convergence trend of ICA is shown in the following figures. Vertical column of these graphs represents the best cost and horizontal column shows the number of iteration. It is observed in all graphs that the more developed is the graph, the better are the results.

Figure 1 is for problem number 7 with 30 suppliers and 10 products; and figure 2 is for problem number 20 with 100 suppliers and 70 products.

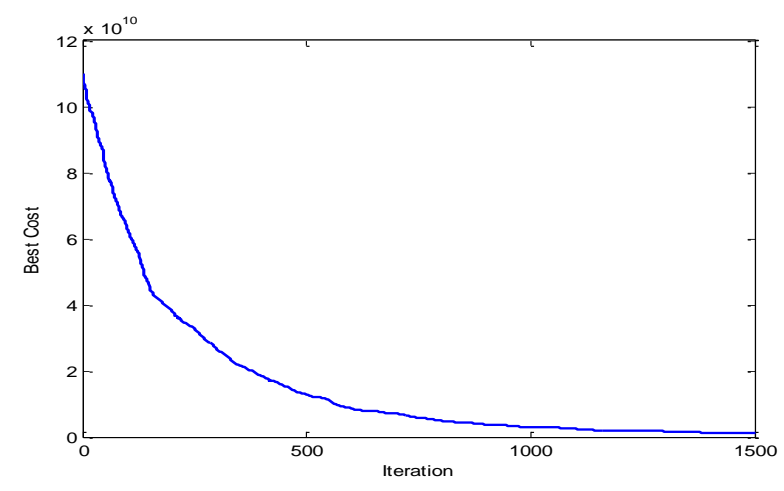

Fig. 1. The relationship between time and cost for problem number 7

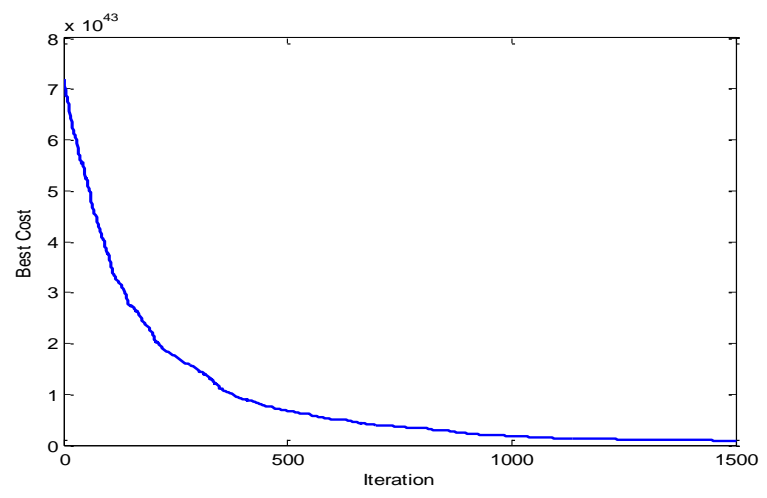

Fig. 2. The relationship between time and cost for problem number 20

\section{F. Sensitivity analysis}

In this section, sensitivity analysis has been used to verify the correctness of modeling and investigate to which parameter changes, objective function is more sensitive. Sensitivity analysis is conducted on three parameters that are the number of suppliers, the number of products, and demand; and the results are shown in following figures in which horizontal axis is for studied variable and vertical axis is for objective function. Figure 3 shows the changes in objective function vs. changes in the number of suppliers, the number of suppliers has been changed from 10 to 100 , and objective function value is calculated for each of them.

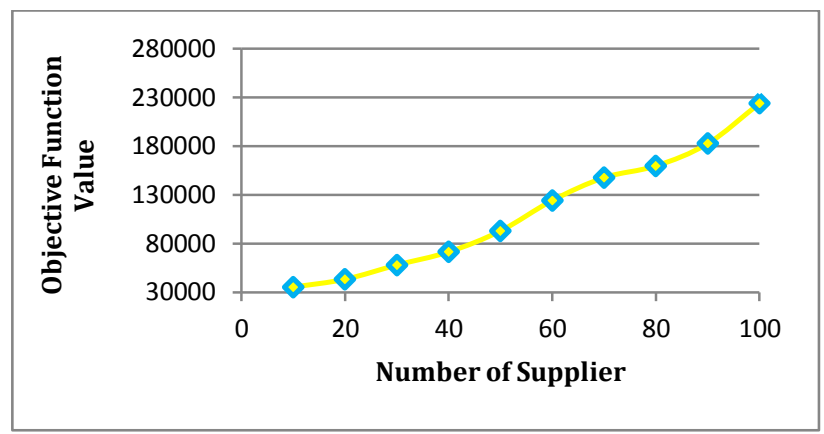

Fig. 3. Changes in objective function value vs changes in the number of suppliers 


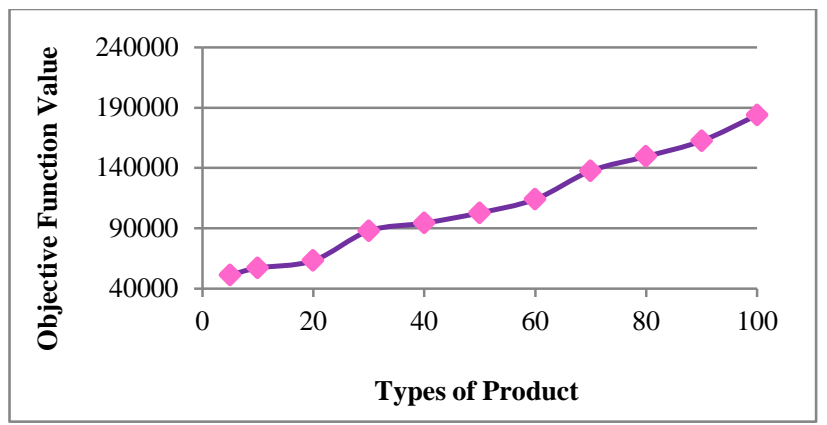

Fig. 4. Changes in objective function value vs. changes in the number of products

Figure 4 shows changes in the objective function value vs. changes in the number of products. The number of products has been increased from 5 to 100 and objective function value is also shown in figure.

Figure 5 shows changes in objective function value vs. changes in demand. Objective function value has increased following an increase in demand. The effect of this parameter on objective function was more significant than any other parameter; therefore, objective function is more sensitive to demand.

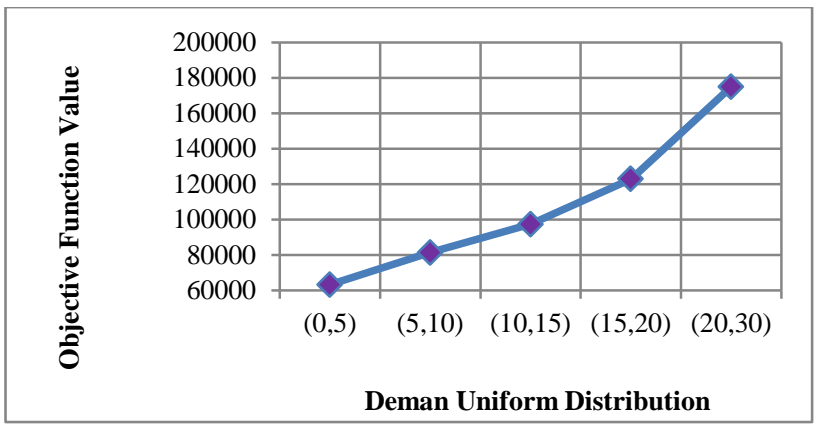

Fig. 5. Changes in objective function value vs. changes in demand

\section{CONCLUSION}

In this paper, first mathematical model due to the restrictions of Sazeh Gostar Saipa (S.G.S) Company has been studied. Then a solution is proposed for this model which follows the imperialist competitive algorithm. It is then compared on a small scale with Gams and its superiority is verified. The distribution of input data, parameter set, result tables, and graphs is demonstrated and 20 numerical samples are presented to further the understanding of the problem. Since GAPs are less than 6\%, and responses are obtained in a reasonable time, it can be concluded that imperialist competitive algorithm has been true. Then to verify the correctness of model, sensitivity analysis has been conducted on three parameters, and finally the results show that the model has demonstrated a great sensitivity to demand. Future research could be present developing mathematical model with greater levels of supply chain and with the more different number of vehicles and producers or distributors and comprehensive development model suggested the results with the different algorithms and analyze, and also a multi-objective considering several important objectives simultaneously to review the performance of ICA algorithm in resolving these issues.

\section{REFERENCES}

[1] Baumol, W.J., Vinod, H.D. "An inventory theoretic model of freight transport demand", Management Science, 16, 1970, 413-421.

[2] Yokoyoma. "Integrated optimization of inventory - distribution systems", proceedings of eighteenth International conference on computers and industrial engineering, 10, 1995, 479-484.

[3] Kim, JU, Kim, Y. "A Decomposition Approach to a Multi-period Vehicle Scheduling problem", Omega, International Journal of Management, 27, 1999, 421-430.

[4] Asgari, a., Aghdasi, d., "a model of integrated inventory and transportation planning in supply chain management: Iran Khodro", the first national conference on logistics and supply chain, Tehran, Iran,2004,10-19.

[5] Jang, YJ, Jang, SY, Chang, BM, Park, J. "A combined model of network design and production / distribution planning for a supply network", Computers and Industrial Engineering, 43, 2012, 263 - 281.

[6] Karabuk, S. "Modeling and optimizing transportation decision in a manufacturing supply chain", Transportation Research part E, 43 (4), 2007, 321 - 337.

[7] Chou, A.S.C., Cheng, T.C.E., Lin, B.M.T. "Scheduling in an assembly type production with batch transfer", Omegan, 35 (2), 2007, 143-151.

[8] Zegordi, SH, Kamal Abdi, IN, Beheshti Nia, MA "A novel genetic algorithm for solving production and transportation scheduling in a twostage supply chain", Computers \& Industrial Engineering, 58, 2010, 373-381.

[9] David, N., surico, M., Turchiano, B., Kaymak, U. "Genetic algorithms for supply-chain scheduling: A case study in the distribution of readymixed concrete", European Journal of operational research, 177 2007, 2069-2099.

[10] Zandieh, Z., Molla Alizadeh, S. "synchronizing production and air transportation scheduling using mathematical programming models", Journal of computational and Applied mathematics, 230, 2009, 546 558.

[11] Ghasemi, n., Joiner, M. "multiplexing orders and the timing of mathematical modeling send to help in the supply chain", the National Conference of logistics and supply chain, Tehran, Iran,2011,15-35.

[12] Chen, A.Z., Liu, S.C. "Variable neighborhood search for the inventory routing and scheduling problem in a supply chain", Expert system with application, 39, 2012, 4149-4159.

[13] Pundoor, G., Chen, Z.L. "Joint cyclic production and delivery scheduling in a two - stage supply chain", production Economic, 119, 2013, 55-74.

[14] Rohit Bhatnagar., Peeyush Mehta., Chee Chong Teo. "Coordination of planning and scheduling decisions in global supply chains with dual supply modes", Production Economics, 131, 2011, 473-482.

[15] Elimam, AA, Dodin, B. "Project scheduling in optimizing integrated supply chain operations", European Journal of Operational Research, 224, 2013, 530-541.

[16] Hishamuddin, H., Sarker, RA, Essam, D. "A recovery model for a twoechelon serial supply chain with consideration of transportation disruption", Computers \& Industrial Engineering, 64, 2014, 552-561.

[17] Osman, Hany., Demirli, Kudret. "Economic lot and delivery scheduling problem for multi-stage supply chains, 136, 2012, 275-286.

[18] Kim, Y.D., Kang J.H. 2009. "Coordination of inventory and transportation managements

[19] Zegordi, SH, , Beheshti Nia, MA " Integrating production and transportation scheduling in a two-stage supply chain considering order assignment ", The International Journal of Advanced Manufacturing, 44, 2009, 928-939. 